\title{
Heating Problems When Using the Converter Station Grounding Grid as the HVDC Grounding Electrode
}

\author{
Huaifei Chen ${ }^{1, a}$, Zhuohong Pan ${ }^{1, b}$, Huifan $X^{2}{ }^{2}$, Bo Tan $^{3}$ and Xuefang Tong ${ }^{3}$ \\ ${ }^{1}$ School of Electrical Engineering Wuhan University, Wuhan 430072, China \\ ${ }^{2}$ China Southern Power Grid, Guangzhou 510623, China \\ ${ }^{3}$ China Electric Power Research Institute, Wuhan 430074, China \\ a1632682009@qq.com, 'leekey2@163.com
}

\begin{abstract}
Keywords: convertor station grounding grid grounding electrode
Abstract: To ensure the safe and stable operation of HVDC systems without grounding electrode, this paper proposes a concept of replacing the HVDC grounding electrode with the converter station's grounding grid. This paper studies the technical problems of heating problem of grounding grid. The result shows that the ground down lead can't bear DC current in a long-term, which means the ground return current utilizes the feeder cable to run into the grid. The permitted operating time when the ground return current is 3000A should be limited within 10 minutes. If an HVDC link uses bipole blocking control strategy, the research helps eliminating the HVDC grounding electrode, which will greatly save the cost.
\end{abstract}

\section{Introduction}

Grounding electrode is an important part of HVDC links. However, because of some external factors such as land expropriation, HVDC grounding electrodes cannot go into operation as scheduled in the process of engineering construction, which makes HVDC links to defer their implementation. To save the cost and get rid of the constrain of HVDC grounding electrodes, an operating mode for HVDC without grounding electrode has been presented in [1], which has also been applied the China Southern Power Grid. Using the converter station grounding grid as the HVDC grounding electrode is a practical solution for HVDC links without grounding electrodes. However, it will come with many problems, including secondary equipment and personal safety, heating and corrosion problem of the converter station's grounding grid. Among all these problems, heating is a major issue under the no grounding electrode mode. Therefore, we need to do further research on heating issues [2][3].

\section{Differences Between Grounding Grid and DC Grounding Electrode}

The differences between grounding grid and DC grounding electrode are as follows:

1) Generally, the soil resistivity of converter station is several times higher than that of HVDC grounding electrode site, and the equivalent area of converter station grounding grid is smaller. So the converter station grounding grid cannot stand rated current in earth for a long time.

2) The thermal conductivity of converter station site soil usually is higher than HVDC grounding electrode site, while the specific heat is smaller. So the soil heating problem is more serious.

3) The converter station grounding grid is buried deeper. the step potential is higher. The converter station must consider the problem of contact potential difference.

4) Standard about step potential of converter station is easier to meet, comparing to HVDC grounding electrode. 
5)Converter station grounding grid presents a grid shape, so the distribution of leakage current is more not uniform, leakage current density of the marginal conductor of the grounding grid is much larger than the DC grounding electrode.

6) The conductor cross-sectional area of converter station grounding grid is much smaller than that of DC grounding electrode, large leakage current will case thermal stability problem when pitting corrosion occurs.

7) When ground return current enters converter station grounding grid, the DC current will flee into the $\mathrm{AC}$ system, causing DC biasing problem in power transformer.

8) When we replace grounding electrode with grounding grid, we need to pay attention to thing that ground return current may have effects on other systems, such as pipelines, railways and so on.

\section{Analysis on the Heating Problem of Grounding Grid}

\section{The Calibration of the Thermal Stabilities of the Ground Gown Lead and the Horizontal Conductor}

1) The calibration of the thermal stability of the conductor when the unbalanced current applied

At present, the maximum current of the bipolar imbalance operation mode will not exceed $1 \%$ of the rated current in all of the HVDC transmission projects in the country. For example, in the general DC transmission, the grounding current of the bipolar imbalance operation mode is less than 100A. Under this operating condition, the thermal stability of the grounding conductor meets the requirement, so it only needs to check the operating condition of the ground return operation mode

2) The calibration of the thermal stability of the conductor when the ground return operation current applied

By using the finite element analysis software, the thermal stability of the ground return current is calibrated. The thickness of flat steel is $7 \mathrm{~mm}$, and the length is $50 \mathrm{~mm}$, as shown in Fig.1. The thermal conductivity is $50 \mathrm{~W} /(\mathrm{m} \cdot \mathrm{K})$. The temperature of the steel is $400 \square$ in a steady state, current magnitude applied to the steel is then calculated. Direct current is applied to the top side of the steel, and the bottom side of the steel is grounded, the convective heat transfer coefficient between the steel and the outside is $10 \mathrm{~W} /(\mathrm{m} 2 \cdot \mathrm{K})$, which is applied to all the border of the steel.

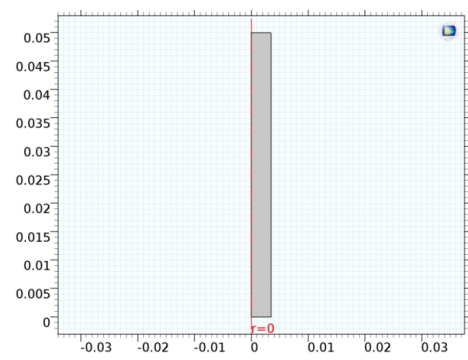

Fig. 1 the simulation model of the thermal stability of the ground

down lead line when the ground return operation current applied

When the electronic conductivity of the steel is $5 \mathrm{e} 6 \mathrm{~S} / \mathrm{m}$, set the parameter of the current to parameter scanning. When the current is $129 \mathrm{~A}$, the temperature distributing diagram is shown in Fig.2. The maximum of the voltage is $0.033 \mathrm{~V}$. The natural convection heat dissipation is achieved through the air surrounding the steel, so the central temperature of the steel is a little higher, reaching $398{ }^{\circ} \mathrm{C}$, the top and the bottom side of the steel is distant from the center, the temperature is $396.9{ }^{\circ} \mathrm{C}$.

When the electronic conductivity of the steel is $5.89 \mathrm{e} 6 \mathrm{~S} / \mathrm{m}$, set the parameter of the current to 
parameter scanning. When the current is $140 \mathrm{~A}$, the temperature distributing diagram is shown in Fig. 3. The maximum of the voltage is $0.033 \mathrm{~V}$. The central temperature of the steel is $397.9^{\circ} \mathrm{C}$, the temperature of the top and the bottom side of the steel is $396.9^{\circ} \mathrm{C}$.

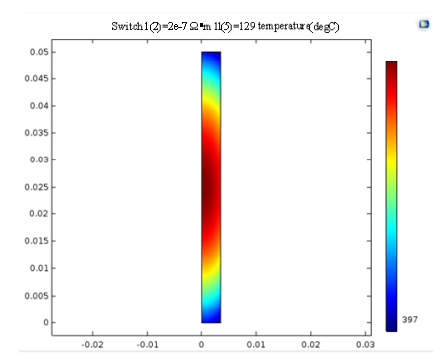

Fig.2 the temperature distributing diagram when the electronic conductivity is $5 \mathrm{e} 6$

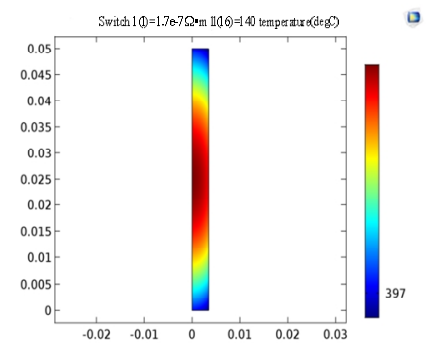

Fig. 3 the temperature distributing diagram when the electronic conductivity is $5.89 \mathrm{e} 6 \mathrm{~S} / \mathrm{m}$

The simulation result shows that the temperature of the ground down lead under the condition that the ground return current is more than 150 A can exceed the standard of $400{ }^{\circ} \mathrm{C}$. At present, the heat transfer characteristic is not desirable, the resistivity is high and the section area of the conductor is relatively small, so the ground return current requires feeder cable.

\section{Analysis on the Grounding Grid's Temperature Rise in Steady State}

The calculation formula of the grounding grid's temperature rise in steady state is as follow.

$$
\tau_{m}=\frac{I^{2} R^{2}}{2 \lambda \rho} .
$$

The range of the ground resistance in a typical converter station is $0.1 \Omega$ to $0.4 \Omega$, and the range of the equivalent ground resistivity is $50 \Omega$ ûm to $500 \Omega$ ûm. Set $I=500$ A and $I=1000$ A respectively, the results are shown in Fig.4 and Fig.5.

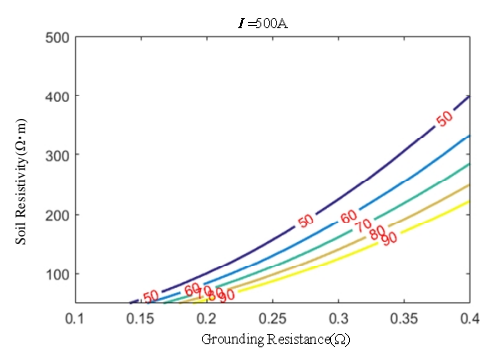

Figure 4 the temperature rise in steady state and the ground resistance-ground resistivity curve when the ground return current is $500 \mathrm{~A}$

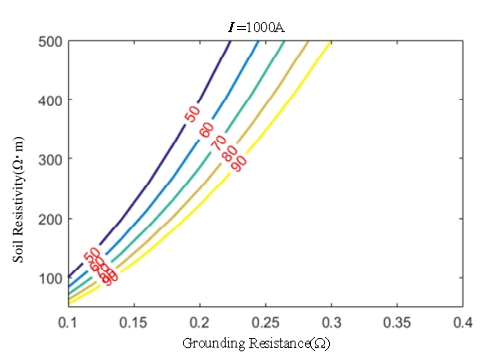

Figure 5 the temperature rise in steady state and the ground resistance-ground resistivity curve when the ground return current is $1000 \mathrm{~A}$

The numbered isothermal curves that Fig. 4 and Fig. 5 shows is the variation of temperature rise in steady state as the ground resistance and the resistivity varies. In a steady state, the maximum temperature is $60{ }^{\circ} \mathrm{C}$, and there is $70 \%$ probability that the current of $500 \mathrm{~A}$ can meet the requirement of steady-state temperature rise. If the ground return current reaches $1000 \mathrm{~A}$, there is only about $20 \%$ of the probability that it will meet the needs.

Unlike the DC pole, the ground return current that the grounding grid can withstand in a long-term is smaller, which is generally difficult to achieve rating current in the DC transmission. It is acknowledged that the ground return current that the grounding grid can withstand in a long-term should be less than 1000A. 


\section{Analysis on the Transient Grounding Grid's Temperature Rise}

The temperature rise-time curve of the ground is as follow.

$$
\tau=\tau_{\omega}\left(1-e^{-\frac{t}{T_{r}}}\right) .
$$

In the formula, $\tau_{\omega}$ is the steady-state temperature rise of the ground; $T_{r}$ is the time constant of the temperature rise, which is related to the partial surface current density through the ground conductor.

$$
T_{r}=\frac{\tau_{\omega} \gamma}{J^{2} \rho}=\frac{\gamma V^{2}}{2 \lambda J^{2} \rho^{2}}
$$

The surface current density of the conductor $J$ has been simplified as follows. When the ground return current is drawn into the grounding grid, the surface current density through the ground conductor is not uniform, and the average line current density of a grounding grid is defined as follows.

$$
C_{0}=\frac{I}{L} \text {. }
$$

In the formula, $I$ is the ground return current, $L$ is the sum of the length of the grounding grid conductor. And the maximum of the line current density is defined as follows.

$$
C_{\max }=k C_{0}=k \frac{I}{L} \text {. }
$$

In the formula, $k$ is the current uneven coefficient of grounding grid conductor. And the maximum of the surface current density is as follows.

$$
J_{\max }=\frac{C_{\max }}{S}=\frac{k I}{L S} .
$$

The value range of $k$ is set from 5 to 10 , the value of the ground return current is set as 3000A, and the sum of the length of the grounding grid conductor is set as $20000 \mathrm{~m}$ and $40000 \mathrm{~m}$ respectively. The section size is $50 \mathrm{~mm} \times 7 \mathrm{~mm}$, the ground resistivity varies from $50 \Omega$ ûm to 500 $\Omega$ ûm. The calculation results of $T_{r}$ are shown in Fig.6 and Fig.7.

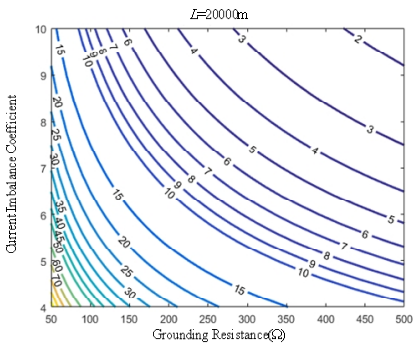

Fig.6 The time constant of the temperature rise when the $\mathrm{L}$ is $20000 \mathrm{~m}$

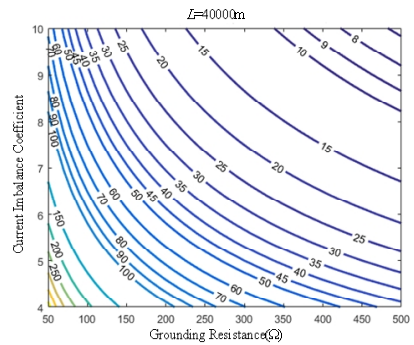

Fig. 7 The time constant of the temperature rise when the $\mathrm{L}$ is $40000 \mathrm{~m}$

When the value of $T_{r}$ is acquired, the permitted operating time when the converter station grounding grid substitutes the DC pole can be calculated by using (2). 


$$
t_{m}=-T_{r} \log \left(1-\frac{\tau_{m}}{\tau_{\omega}}\right)
$$

As $\tau_{\omega}<<\tau_{m}$, the (7) can be approximate expressed as follows.

$$
t_{m} \approx \frac{\tau_{m}}{\tau_{\omega}} T_{r}
$$

When $\tau_{\omega}=1,500{ }^{\circ} \mathrm{C}, t_{m}=60{ }^{\circ} \mathrm{C}$, and put it into (8), the result is as follows.

$$
t_{m} \approx 0.04 T_{r} \text {. }
$$

It has shown that the ground return current drawn into the grid must be limited under the level that can maintain the steady-state temperature rise in the safe range within the time $t_{m}$, or else it will lead to partial soil sintering which will eventually make the grid not work properly. In some extreme cases, the $T_{r}$ might be under $2 \mathrm{~h}$, making the permitted operating time is only $5 \mathrm{~min}$ when the ground return current is $3000 \mathrm{~A}$.

\subsection{Methods to Extent the $T_{r}$}

Theoretically, the grounding grid has the edge effect, and the surface current density of the edge of the grid conductor is relatively higher, if the coke bed can be added to the edge of the conductor, and the current uneven coefficient of grounding grid conductor can be reduced, the $T_{r}$ can be extended.

\section{Conclusion}

A new thought that the converter station grounding grid can serve as DC grounding electrode is proposed, and it has solved the construction problem of the grounding electrode caused by the land location and other external reasons during the process of practical engineering and the subsequent construction problem of DC transmission double-electrode project.

The ground down lead can't serve as the carrier of the ground return current in a long-term, and the ground return current utilizes the feeder cable to run into the grid. In general, the ground return current applied to the grid should be less than 1000A, the permitted operating time when the ground return current is $3000 \mathrm{~A}$ should be limited within 10 minutes.

\section{Literature References}

[1] ZHUYihua, GUO Qi, LI Shuyong, GUAN Hongbing, ZHU Taoxi, XIE Huifan. Realization of High Voltage Direct Current Operating Without Grounding Electrode. Automation of Electric Power Systems, vol. 40, no. 16, pp. 153-158, Aug 2016.

[2] F. Chen, B. Zhang, and J. He, "Influence of Coke Bed on HVDC Grounding Electrode Heat Dissipation," IEEE Transactions on Magnetics, vol. 44, no. 6, pp. 826-829, 2008.

[3] J. E. T. Villas, and C. M. Portela, "Soil heating around the ground electrode of an HVDC system by interaction of electrical, thermal, and electroosmotic phenomena," IEEE Transactions on Power Delivery, vol. 18, no. 3, pp. 874-881, 2003. 